\title{
Efficiency of private flood proofing of new buildings - adapted redevelopment of a floodplain in The Netherlands
}

\author{
B. Gersonius ${ }^{1}$, C. Zevenbergen ${ }^{1,2}$, N. Puyan $^{2}$ \& M. M. M. Billah ${ }^{1}$ \\ ${ }^{1}$ Department of Urban Water and Sanitation, \\ UNESCO-IHE Institute for Water Education, P.O. Box 3015, \\ 2601 DA Delft, The Netherlands \\ ${ }^{2}$ Dura Vermeer Group NV, P.O. Box 3098, 2130 KB Hoofddorp, \\ The Netherlands
}

\begin{abstract}
A number of cities in Europe's deltaic and coastal regions, such as the London metropolis, Hamburg and Dordrecht, share in part similar challenges such as (re)development activities and expansions onto floodplains and they recognize the need for new planning approaches to manage actual and future flood risks in these areas. The tendency is now to look for new ways to distribute responsibilities between different types of stakeholders, so as to take advantage of different initiatives over differing spatial scales, from the catchment level down to the individual building level. In this respect, there is a clear need to include resilience measures taken at the lowest spatial level as part of a top-down and bottom-up approach. This kind of measure comprises flood proofing of buildings and associated infrastructure as well as adapting building activities to the risk. The extent to which such measures will be provided will probably be dictated by micro and macro economic factors. However, as of yet information on their performance is limited, which particularly holds true for the Dutch context. Consequently, the economic efficiency of these technologies is unclear.

In this paper a new database containing economic information involving the costs and benefits for implementing these measures is presented. Flood damage databases have been constructed from a synthesis of all data available from both secondary sources, such as the ABI and FEMA database, and from the real experience of floods. The data is built up from knowledge about the effect of flood water on both the fabric of the building and its contents. In order to investigate the efficiency of private flood proofing of buildings, benefit cost analyses for different building types and elevations are conducted for a case study in Dordrecht, the Netherlands. The benefit for each damage reduction strategy is calculated by estimating the difference in expected annual losses compared to the traditional way of building.

Keywords: flood proofing, economic efficiency, urban (re)development, urban flood management, resilience.
\end{abstract}




\section{Introduction}

In the Netherlands local efforts to integrate urban flood management with the upgrading of existing urban areas are providing valuable experience for the development of a holistic approach in which the resilience of the entire system is enhanced. Resilience reflects the capacity of complex adaptive systems to cope with disturbance (for example, floods) and to reorganize while undergoing change (for example, climate and socio-economic change) [1]. A resilient approach may be dedicated to accommodating floods, with concurrent impact minimisation and rapid recovery. As part of this approach, the form of buildings, their occupation and use of materials will need to consider the range of flood conditions to which they may be exposed. The area as a whole is more resilient if land uses that are flood-compatible (e.g. informal open spaces and floating spaces) are planned in the highest risk areas, and if essential infrastructure, vulnerable uses and increased housing densities are directed towards areas of low (residual) risk and are being safeguarded longest. This implies diversifying measures and defence levels for different land uses according to their vulnerability, based on the costs and benefits of different solutions.

It is arguable that opportunities created by urban transformation and restructuring can be used to implement additional or even new flood mitigation measures, and thereby to deliver resiliency. In this respect, private flood proofing measures could make a particularly important contribution to urban planning objectives, such as to revive the urban waterfront, because they do not have to hinder urban development. However, the adoption and effective implementation of urban flood management into urban planning practices is hampered by the following main factors [2]:

- Lack of understanding current and future risks and implications: flood frequency is likely to increase during lifetime buildings;

- Lack of long-term planning, and poor integrated and comprehensive planning;

- Inadequate steering role local and regional authorities, and conservative nature of the building sector.

Currently a number of aspects of an integrated approach to urban flood management are relatively new to (local) decision-makers, (urban planning) professionals and socio-economic sectors. One of the main issues that need indepth attention is to decide at the extent to which measures will be provided. Research will also need to provide sound information to inform the choice between reducing the probability of floods by reinforcing protection works versus the reduction of potential impact of floods by adapting the built environment (or a combination of both measures). Current knowledge and data are insufficient to reliably quantify the effectiveness and efficiency of adaptation strategies. Moreover, scientific knowledge is often fragmented and not readily accessible to stakeholders. This makes it difficult to establish a long-term management strategy.

The recent Urban Flood Management (UFM) project, which aims at the development and verification of UFM strategies and methodologies in the cities 
of Dordrecht, Hamburg and London, may provide relevant practical examples to address these issues. These experiences could contribute to local, regional and national climate change adaptation policy making and the results might increase the (political) willingness to prioritise adaptation measures. This paper presents the development of a new database containing economic information involving the costs and benefits for implementing private flood proofing measures. The Dordrecht example will be used as a case study to evaluate the efficiency of various measures.

\section{Review and definitions of flood proofing measures}

This paper concentrates on measures that could be carried out by local authorities, building companies or householders, and also those that could be appropriate for grant assisted schemes. They comprise individual flood proofing of buildings and municipal infrastructure and adapting the building activities to the risk. Flood proofing can be accomplished by four defence strategies, using elevated configuration, dry proofing the building by sealing or shielding, wet proofing the building, and using floating or amphibious solutions.

In the first strategy the entire structure is elevated to prevent the entrance of flood water, e.g. by building on columns, walls, or embankments. Dry proofing involves sealing, where the external walls are used to hold back the flood water, or shielding, where the flood water is kept out of the building by installing permanent or temporary water barriers. Shielding strategies can generally be used for floods of up to one meter depth but should not be used above this depth of water. Wet proofing is based on the acceptance that some water will enter the building, so the intention is to use materials that will help minimize the impact of water on fabric and fixtures. The fourth strategy entails floating or amphibious buildings that can move with a fluctuating water level.

Flood adapted building use means that endangered storeys are not used costintensively, and that no expensive upgrading is undertaken. As an example, designing dwellings with a non-habitable ground floor may be considered as an alternative for redevelopment projects. The ground floor could be used for flood compatible uses such as car parking, flood resilient storage, public open space, etc. (fig. 1). However, this measure can sometimes have adverse consequences for the appearance of the streetscape and for perceptions of public safety and security. Solutions such as mixed-use development with commercial uses on the ground floor can provide more active frontages, but may be limited by the market.

Private precautionary measures have a significant potential to safeguard buildings and contents from flooding. Dry proofing can keep the water out of the property, particularly for shallower floods, or buy time for the householder to move valuable possessions upstairs. When the inflow of water into the building cannot be prevented, repair costs can be reduced through wet proofing and flood adapted use. However, data on the costs and effects of such measures are rare, and consequently, the economic efficiency of different technologies is unclear. 


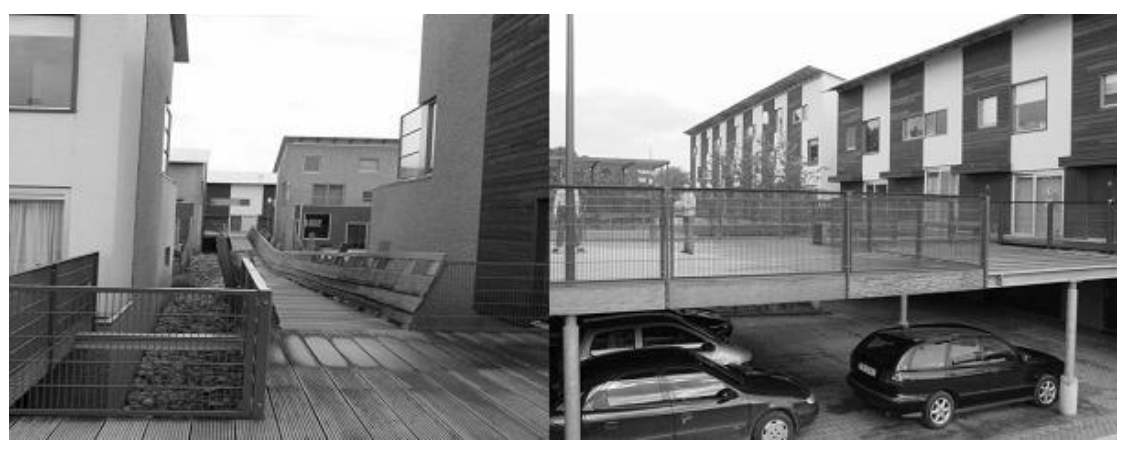

Figure 1: $\quad$ Example of adapted building use.

This research presents new insights with respect to the costs and benefits of implementing various private flood proofing measures presented in an earlier manuscript in Zevenbergn et al. [3]. Perhaps the first analysis of flood damage reduction measures taken at individual building level is by the USACE [4]. More recently, the ICPR have evaluated the effectiveness of various flood proofing measures depending on their capability to reduce the damage potential [5]. The ICPR publication indicates that flood proofing measures are mainly effective in areas with frequent flood events and low flood depths. However, Kreibich et al. [6] mention that it remains unclear on which data basis these estimates rely. Therefore they have interviewed about 1200 private households, which were affected by the 2002 flood at the river Elbe, about their flood damage as well as about their flood proofing measures. This survey has shown that even during this extreme flood event many of the measures led to significant mean damage reductions of up to $53 \%$ for buildings and contents. The most effective ones were wet proofing measures, namely flood adapted use and flood adapted interior fittings. Dry proofing measures and private flood walls had no or only little effect, because many of the structures were overtopped. Another recent research study by Bowker [7] makes broad estimates of the costs and benefits of a range of flood proofing solutions.

\section{Development of the flood damage database}

Different approaches to flood damage data collection have been used in practice. The current state-of-the-art in evaluating damages and the key principles and procedure of constructing a flood damage database have been provided by the work done in the FLOODsite project [8]. The approach that has been adopted for this study is termed the synthetic approach. It means that that the approach involves a synthesis of all available data, from both secondary sources and from the real experience of floods. The reason to use synthetic data is that in the Netherlands flood damage data is not available for households that have undertaken building precautionary measures. Note that the very high safety design standards of the Dutch collective protective system have discouraged people to implement private measures. 
Building damage and failure arise from a range of flood actions such as: hydrostatic actions, hydrodynamic actions, erosion, buoyancy, debris and contamination [9]. For the development of the loss estimation model the most relevant failure mechanisms and the combination of factors that result in damage (or even failure) potential have to be identified. Damage influencing factors can be classified into flood impact variables (water level, velocity, etc.) on the one hand and the structure resistance variables (type of building, precautionary measures) on the other hand [10]. Finally, the relation of these variables with the building as well as content damage should also be investigated. Therefore, this paper analyses two failure mechanisms, (1) collapse of walls and (2) immersion by flood water, that are thought to be most relevant for the Dordrecht case.

For the purpose of assembling the synthetic database for flood damage to new built-up areas it was decided to use the Pre Choice System (PCS) housing construction concept, developed by Dura Vermeer [11], as the basis for the analysis. This concept allows for the construction of different house types on the basis of one standard type, fig 2 . The principle reason for using the PCS-type house is that its basis and measurements are fixed and that the costs are known. Five type structures are analysed in this study. These are,

1. Semi detached property with a ground floor area of $63 \mathrm{~m}^{2}$;

2. Terraced property with a ground floor area of $48 \mathrm{~m}^{2}$;

3. Terraced property with a ground floor area of $39 \mathrm{~m}^{2}$;

4. Ground floor flat with a ground floor area of $81 \mathrm{~m}^{2}$;

5. Bungalow with a ground floor area of $63 \mathrm{~m}^{2}$.

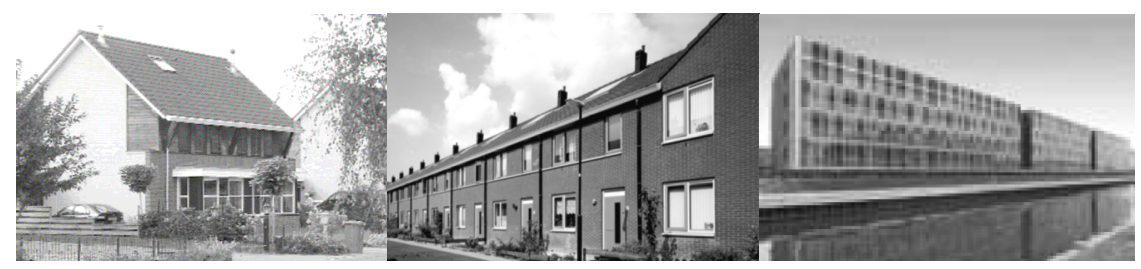

Figure 2: Examples of different house types on the basis of the PCS concept.

The structure walls and floors are concrete. The walls have a brickwork panel on the exterior, with a mineral insulation. The finishing is traditional with a blockwork internal panel, skirting boards, sand-cement screeds, gypsum plaster, chipboard floors, painting, and tiling in the sanitary rooms and kitchen. The structure foundation may be adapted to the local ground conditions. The properties are built without a basement.

\subsection{Failure potential}

Partial collapse of the supporting walls is one of the mechanisms, which may result in failure of the structure. This mechanism can be described by the comparison of the loads on the building with its strength which method has been performed by several studies. The approach given in [12] is used in this paper for 
calculating the possibility of the collapse of walls by hydrostatic and hydrodynamic pressure. From the resulting damage curve (fig. 3) it can be concluded that the concrete structure will not be damaged within the typical ranges for water depth and velocity associated with natural floodwaters on floodplains (such as for the Dordrecht example).

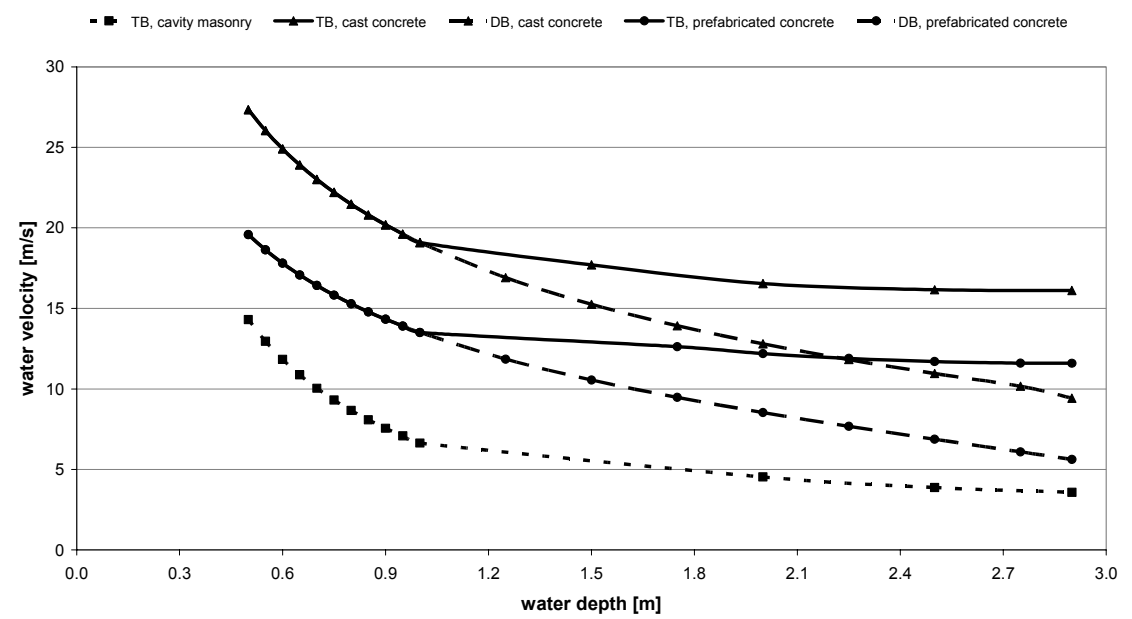

Figure 3: Damage curve for hydrostatic and hydrodynamic pressure.

\subsection{Damage potential}

This step assembles information on the susceptibility of the structure to damage with immersion by flood water. Therefore different repair costs for the building fabric and different susceptibility values of the contents were determined by the depth of flooding. This was done by means of a desk study of available data from secondary sources, next to consulting an expert (loss adjuster).

Cost groups / items for the building fabric include,

- Clean-up and disinfection

- External main building (mineral insulation)

- Internal walls, ceilings and covering (gypsum plaster, restroom tiling and kitchen tiling)

- $\quad$ Floor covering (sand-cement screeds and chipboard floor)

- Doors, windows and frames

- Stairs

- Kitchen and cupboards

- Plumbing and electrical installations

- Other installations

- Service meters

- Heating system (painting) 
In case of the building fabric $100 \%$ susceptibility was assumed. Information on susceptibility values for the contents of the building was obtained from FEMA [13], table 1. The value of average total contents per dwelling is estimated at $€ 70,000$ for the Netherlands after a study by www.ineas.nl, an insurance company [14].

Table 1: $\quad$ Susceptibility of contents (FEMA [13]).

\begin{tabular}{|l|l|l|l|l|l|l|l|l|l|}
\hline Flood depth [m] & 0.3 & 0.6 & 0.9 & 1.2 & 1.5 & 1.8 & 2.1 & 2.4 & $>2.4$ \\
\hline $\begin{array}{l}\text { Damage for 2 or more } \\
\text { stories, no basement [\%] }\end{array}$ & 13.5 & 19.5 & 27.0 & 30.0 & 33.0 & 36.0 & 39.0 & 43.5 & 49.5 \\
\hline $\begin{array}{l}\text { Damage for 1 story, no } \\
\text { basement [\%] }\end{array}$ & 21.0 & 33.0 & 40.5 & 43.5 & 45.0 & 60.0 & 64.5 & 66.0 & 67.5 \\
\hline
\end{tabular}

Figure 4 shows the suite of depth/damage curves that is the result of the assembly of flood damage data. Note that the database only provides damage data and depth data up to 2.6 meters of flooding, as floods are not expected to exceed 1.0 meter in depth for the Dordrecht case (even in the extreme scenario).

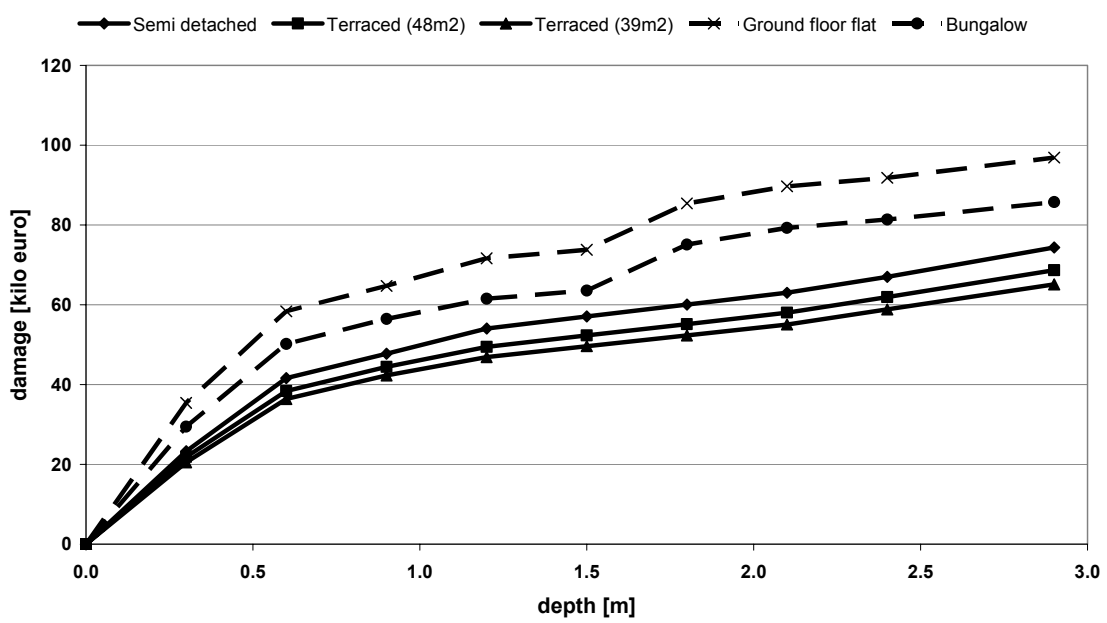

Figure 4: Flood damage curves for the five house types.

\subsection{Effectiveness of flood proofing measures to reduce damage}

Five types of measures that may be taken were analysed,

1. Elevating the structure $0.5 \mathrm{~m}$ and $1.0 \mathrm{~m}$ by building on columns;

2. Elevating the structure $0.3 \mathrm{~m}, 0.6 \mathrm{~m}$ and $0.9 \mathrm{~m}$ by building on walls;

3. Wet proofing until $1.0 \mathrm{~m}$;

4. Temporary dry proofing until $0.9 \mathrm{~m}$ by shielding;

5. Permanent dry proofing until $0.9 \mathrm{~m}$ by sealing;

Typical mitigation options that are considered for the different strategies are: 


\section{Avoidance measures by building on columns}

- Concrete columns

- Exterior concrete stairwell

Avoidance measures by building on walls

- Concrete wall

- Brick masonry

- Concrete stairs

\section{Wet proofing measures}

- Solid concrete slabs

- Plastic flooring

- Closed cell insulation

- Composite internal walls

- Flood resilient kitchen

- Flood resilient doors, windows and frames

- Non return valves in waste pipes and outlets

- Pump and sump

\section{Temporary dry proofing measures}

- $\quad$ Standard door guard

- Airbrick covers

- Non return valves in waste pipes and outlets

\section{Permanent dry proofing measures}

- Sprayed on cement

- $\quad$ Flood resistant external doors

- $\quad$ Non return valves in waste pipes and outlets

- Airbrick covers

- Pump and sump

- Drainage line around perimeter of house

Example costs for building precautionary measures are given in table 2 for the different house types.

Table 2: $\quad$ Cost to implement building precautionary measures.

\begin{tabular}{|l|l|l|l|l|l|}
\hline & \multicolumn{5}{|c|}{ Cost [euro] } \\
\hline Mitigation measure & Type 1 & Type 2 & Type 3 & Type 4 & Type 5 \\
\hline Building on 0.5 m column & 1200 & 1200 & 1200 & 1000 & 1200 \\
\hline Building on 1.0 m column & 1900 & 1900 & 1900 & 1700 & 1900 \\
\hline Building on 0.3 m wall & 2000 & 1800 & 1700 & 1800 & 2000 \\
\hline Building on 0.6 m wall & 3100 & 2800 & 2600 & 3000 & 3100 \\
\hline Building on 0.9 m wall & 4300 & 3800 & 3500 & 4100 & 4300 \\
\hline Wet proofing & 17700 & 16700 & 15400 & 26200 & 19000 \\
\hline Temporary dry proofing & 2300 & 2300 & 2300 & 2300 & 2300 \\
\hline Permanent dry proofing & 7600 & 7000 & 6600 & 8200 & 7600 \\
\hline
\end{tabular}

When a structure is elevated or dry proofed, no damage was assumed to occur to the structure or content until the protection level was exceeded. Residual damage however still remains for flood events above this threshold. 
Furthermore, temporary dry proofing was assumed to be effective only for flood durations up to 24 hours. The damage reduced in case of a wet proofing strategy is computed by subtracting from the total damage the damage (components) reduced with fitting resilience measures: i.e., mineral insulation, gypsum plasterwork, sand-cement screeds, chipboard floor, doors, windows and frames, and kitchen.

An example of the synthetic data assembled for the terraced property is given in fig. 5 .

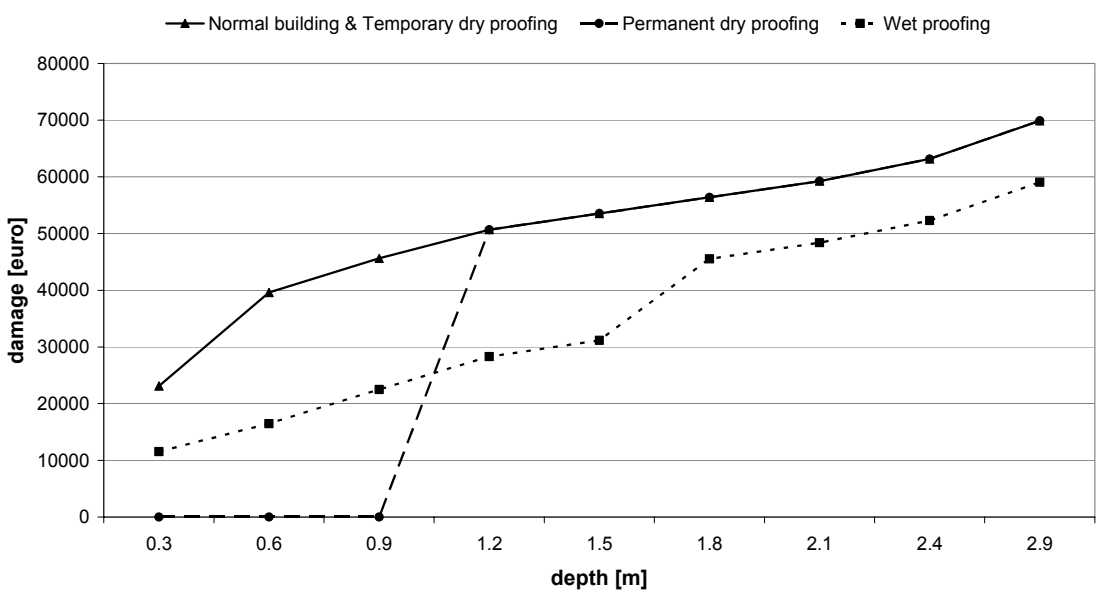

Figure 5: $\quad$ Flood damages curves for terraced property with and without flood proofing measures undertaken (for a flood duration of $>24 \mathrm{~h}$ ).

\section{Efficiency of flood proof redevelopment on a flood plain in The Netherlands}

The above analysis has dealt with event damage evaluation. In order to examine the economic feasibility of precautionary measures, however, it is necessary to assess the exposure of the structure to the full range of water levels to be experienced at the specific regeneration site in the floodplain, Stadswerven and Lijnbaan area (Dordrecht), fig. 6. This usually involves hydraulic modelling to determine the recurrence times of different water levels.

For this study, the exceedance probability of local water levels was simulated using the probabilistic model Hydra-B [15]. This model takes into account the discharge regime of the river Rhine, the sea water level, wind velocities and the control situation of Maeslant- and Hartelbarrier. The simulation was done for the present situation as well as for the year 2050 and 2100 in order to assess the impact of climate change and sea level rise on event probabilities. Figure 7 shows the probability distribution function of water levels for the Beneden Merwede river near Dordrecht (for the medium climate change scenario). 


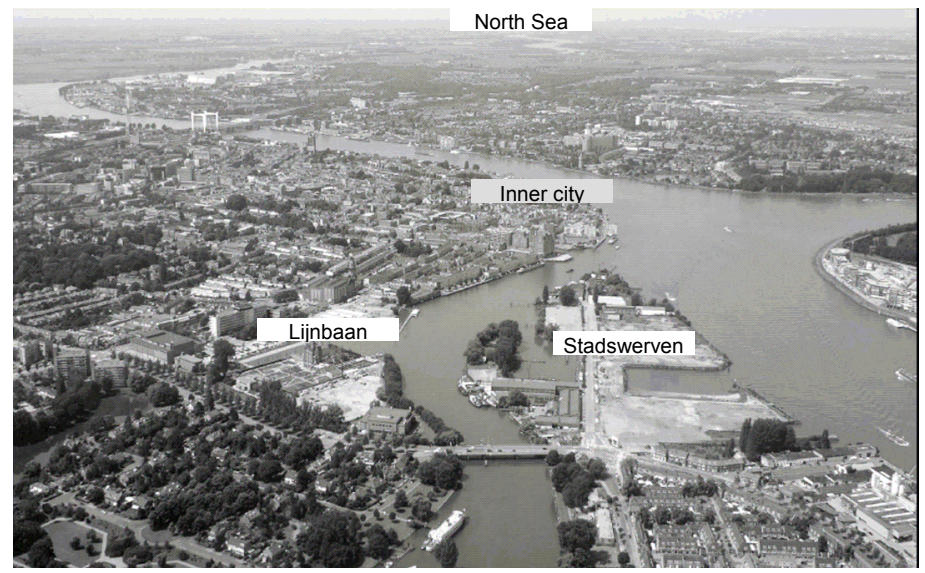

Figure 6: Regeneration site Stadswerven and Lijnbaan area.

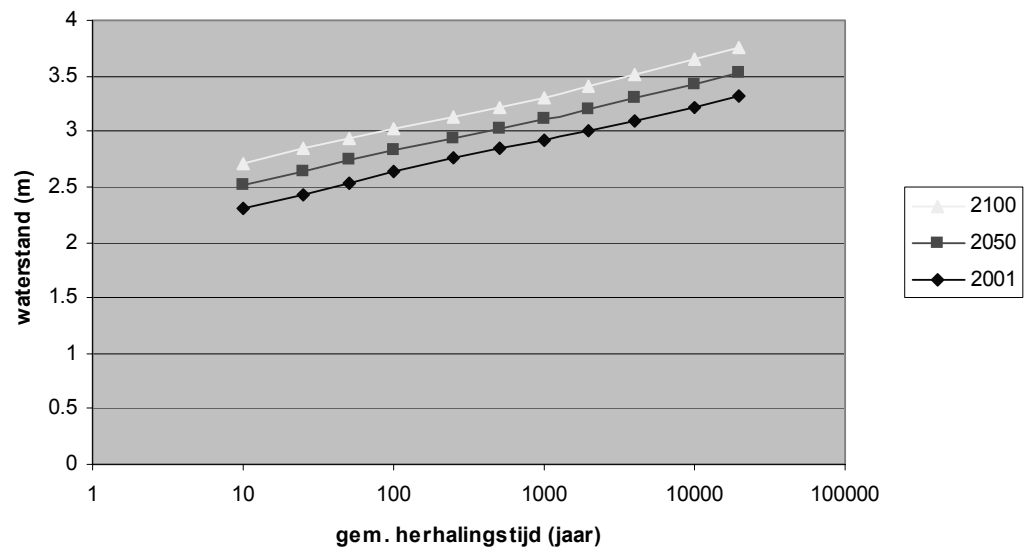

Figure 7: Water-level-frequency relationship for Beneden Merwede river.

The actual land elevation level of the regeneration site (Stadswerven and Lijnbaan area) varies between 2.7 and 3.5 meter +NAP. Hence, the probability of a flood to occur is around 1:250 years for the current situation, 1:50 years for 2050, and 1:10 years for 2010. The City of Dordrecht targets for 1,600 new homes in the coming decade with this regeneration project.

To evaluate the efficiency of flood proofing strategies for the regeneration project, the benefit-cost ratio of each strategy has been computed. The benefitcost analysis has been undertaken over a time horizon of 50 years, which is approximately equal to the engineering life of the structure. The benefit for a damage reduction strategy is calculated by estimating the difference in expected annual losses compared to the traditional way of building. Annual flood damage is computed as the integral of the damage-probability function:

$$
E(S)=\int S(x) d P(x)
$$




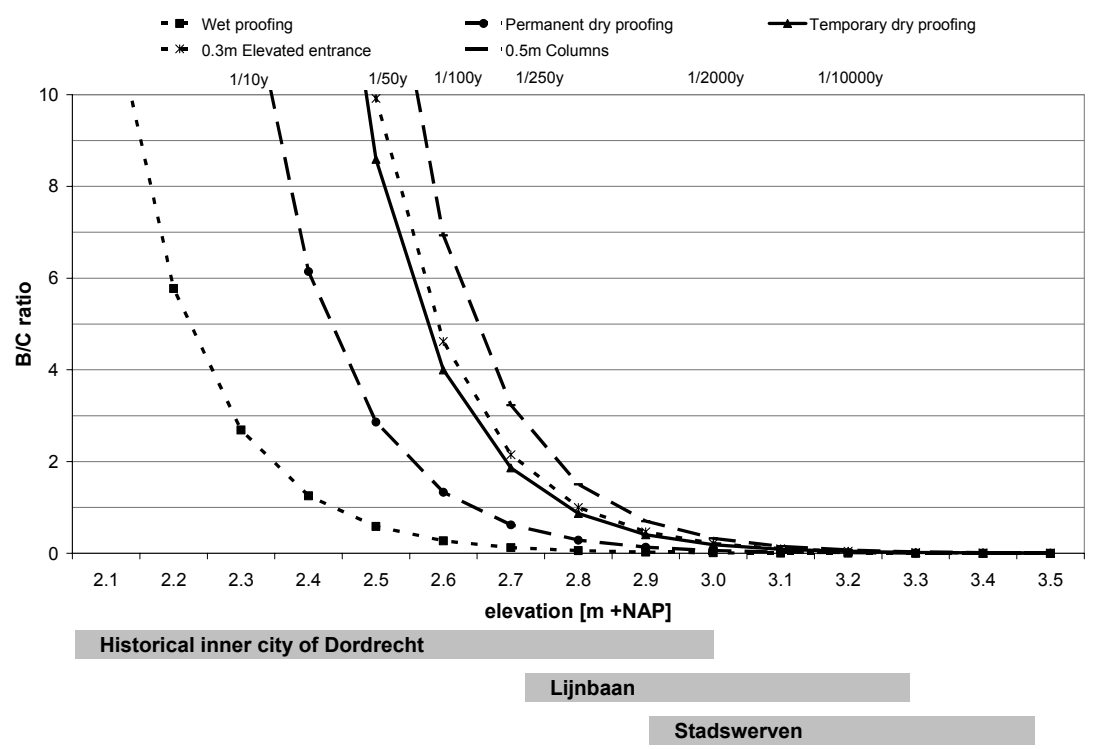

Figure 8: $\quad \mathrm{B} / \mathrm{C}$ ratios as a function of land surface level in $\mathrm{m}+\mathrm{NAP}$ (for a flood duration of $<24 \mathrm{~h}$ ).

where $E(S)$ is the expected annual damage, $S(x)$ is the flood damage caused by flood depth $x$, and $P(x)$ is the probability of flood level $x$. Results of the benefitcost analysis are presented in figure 8 .

The curves show considerable variability depending on the flood proofing strategy and event at the first floor. These data indicate that for a terraced structure (type 2) raising the structure on columns is generally feasible below the 500 year floodplain, and raising on walls below the 400 year floodplain. Temporary dry proofing appears feasible below the 400 year floodplain, whereas permanent dry proofing is only feasible below the 100 year floodplain. Wet proofing a structure is not likely to be feasible above the 25 year floodplain.

It emerges from sensitivity analysis that the relative importance of the different strategies is not particularly sensitive to changes in the water-levelfrequency relationship. On the other hand, the results are more sensitive to changes in costs, and therefore more research is needed to accurately quantify the costs for implementation of private precautionary measures.

\subsection{Choice between reducing probability versus impact of floods}

Figure 9 shows the $\mathrm{B} / \mathrm{C}$-ratios of the different resilience measures compared to elevating the whole area by 0.5 meter (land raising) in relation to the urban density. On the basis of this data, it may be concluded that non-structural responses (NRSs) may be more economically efficient in managing flood losses than structural measures. The construction cost for land raising was estimated at 20 euro $/ \mathrm{m}^{3}$. 


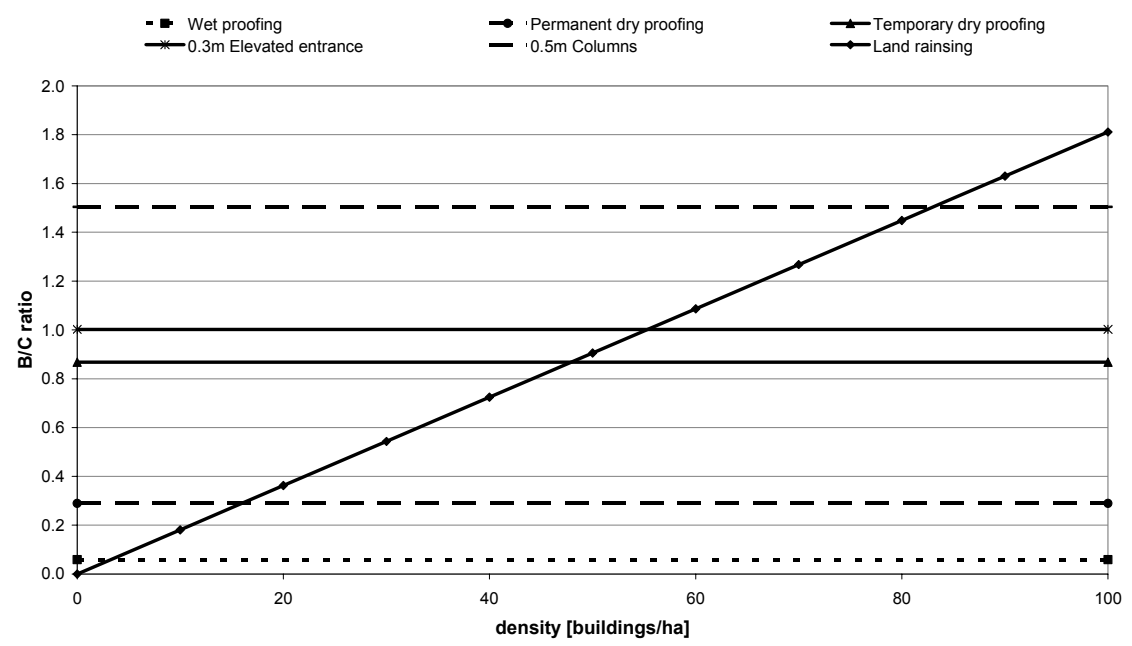

Figure 9: $\mathrm{B} / \mathrm{C}$ ratios for NSRs compared to land raising as a function of urban density.

\section{Discussions and conclusions}

In this paper a new database containing economic information involving the costs and benefits for implementing these measures is presented. The developed database is successfully used to inform the choice between reducing the probability of floods by reinforcing protection works (in this case land raising) versus the reduction of potential impact of floods by adapting the built environment. The NRSs investigated were building the structure on columns, building with an elevated entrance, dry proofing by sealing and by shielding, and wet proofing. From the analysis it emerged building the structure on columns is the most economically efficient measures for the Dordrecht case, which is a flood plain. However, the relative importance of the different strategies is particularly sensitive to changes in implementation costs, and therefore further research on the cost of implementing private precautionary measures is recommended. Also, it was found that NRSs may be more economically efficient in managing flood losses than structural measures.

\section{Acknowledgement}

This work has been supported by a grant from the Living with Water programme.

\section{References}

[1] Walker, B., Holling, C.S., Carpenter, S.R. \& Kinzig, A., Resilience, adaptability and transformability in social-ecological systems. Ecology and Society, 9(2), 5, 2004. 
[2] Szöllösi-Nagy, A. \& Zevenbergen, C., Urban Flood Management, A.A. Balkema Publishers, 2005.

[3] Zevenbergen, C., Gersonius B., Puyan, N., \& Van Herk, S., Challenges in Urban Flood Management (Chapter 13). Advances in Urban Flood Management, eds. Ashley, R., Garvin, S., Pasche, E., Vassilopoulos, A., Zevenbergen, C., Tailor \& Francis Group, London, UK, pp. 299-319, 2007.

[4] Johnson, W.K., Physical and economic feasibility of nonstructural flood plain management measures, prepared for USACE, Ft. Belvoir, VA, 1978.

[5] ICPR, Non Structural Flood Plain Management - Measures and their Effectiveness, International Commission for the Protection of the Rhine, Koblenz, 2002.

[6] Kreibich, H., Thieken, A.H., Petrow, Th., Müller, M. \& Merz, B., Flood loss reduction of private households due to building precautionary measures - lessons learned from the Elbe flood in August 2002, Natural Hazards and Earth System Sciences, 5(2005), pp. 117-126, 2005.

[7] Bowker, P., Flood resistance and resilience solutions: an R\&D scoping study, Department for Environment, Food and Rural Affairs, London, 2007.

[8] Messner, F., Penning-Rowsell, E., Green, C., Meyer, V., Tunstall, S. \& Veen, A. van der, Evaluating flood damages: guidance and recommendations on principles and methods, FLOODsite Report T09-06$01,2007$.

[9] Kelman, I. \& Spence, R., An overview of flood actions on buildings, Engineering Geology, 73(2004), pp. 279-309, 2004.

[10] Thieken, A.H., Müller, M., Kreibich, H., \& Merz, B., Flood damage and influencing factors: New insights from the August 2002 flood in Germany, Water Resour. Res., 41, 2005.

[11] Dura Vermeer Group, http://www.pcs-duravermeer.nl/

[12] Roos, W., Damage to buildings, Delft Cluster Publication DC1-233-9, Delft, 2003

[13] FEMA, State and local mitigation planning how-to guide: Understanding Your Risks, FEMA Publication 386-2, 2001.

[14] Meyer, M. \& Messner, F., National Flood Damage Evaluation Methods A Review of Applied Methods in England, the Netherlands, the Czech Republic and Germany, 2005.

[15] Duits, M., Gebruikershandleiding Hydra-B (3.1 ed.), HKV LIJN IN WATER, Lelystad, 2004. 